\title{
Os dois lados de uma profissão
}

\section{Resumo}

Em se tratando da profissão contábil, além de se ter emprego/trabalho praticamente garantido, as pesquisas mostram que a remuneração ou honorários são significativos, estando à frente de diversas outras profissões tidas como "nobres". De maneira geral, há uma tendência de redução dos empregos diretos na agropecuária e indústrias, setores estes que se caracterizaram como as melhores oportunidades no século que terminou. Fala-se que nos Estados Unidos, nos próximos dez anos, estes dois setores representarão não mais que dois por cento dos empregos daquela economia, ficando para o comércio e serviços o grande filão.

"Diante da atual situação econômica do país, de freqüentes oscilações, pode-se dizer que cresce a importância do profissional de contabilidade. Com base nos dados reais da empresa, o contador pode ser um parceiro importante nas decisões gerenciais". Afirma o presidente do CRC-São Paulo.

Hoje, espera-se que o contador esteja em constante evolução, além de uma série de atributos indispensáveis nas diversas especializações da profissão contábil. Não é mais possível sobreviver no momento atual com aquela postura de escriturador, "guarda-livros", despachante e atividades burocráticas.

$\mathrm{Na}$ verdade, o que desejamos é mostrar que não basta conhecer o perfil do profissional desejado pelo mercado, mas sim, buscar através de pesquisas alternativas que tais habilidades possam ser desenvolvidas durante a graduação, ou pelo menos parte delas.

\section{Abstract}

In concerning to accounting profession, besides one has as practically guaranteed the jobs/employment, researches show that the wages or payments are considerable even beyond several professions had as "noble" ones. In the general manner, there is a trend of reduction in the agribusiness and industries areas with respect to direct jobs, which are characterized by offering the best opportunities in this ongoing century. One says that in the United States, in the oncoming future, those areas will present no more than two percent of the jobs in that economy, remaining for commerce and services the best part of them

"Face to real situation of our country, says the President of CRC - São Paulo, where there are frequent economic oscillations, we can say, it raises the relevance of accountability. The accounting professional is someone who, supported by company real data, can be a helpful partner for the manager decision-making."

Today, we hope that the public accountant be in increasing achievement furthermore a series of attributes which are indispensable in the several accountability specializations. It is no more possible to survive in this moment with those "bookkeeper" or "scribbler" or "forwarding agent" attitudes in the bureaucratic activities.

In fact, what we wish is to show that it isn't enough knowing the required professional profile by the market, but reaching for alternative researches, those skills that can be developed in the undergraduate courses.

\section{Introdução}

Num sentido prático, a primeira maneira de avaliar as perspectivas de uma atividade profissional é saber se existem bons empregos nesta área. A remuneração também é um fator fundamental. Uma boa expectativa de retorno

\footnotetext{
* Prof. Titular da Faculdade de Economia e Administração / USP

**Doutoranda em Controladoria - Faculdade de Economia e Administração / USP
} 
financeiro nos estimula a fazer investimentos mais relevantes na formação profissional.

Em se tratando da profissão contábil, além de se ter emprego/trabalho praticamente garantido, as pesquisas mostram que a remuneração ou honorários são significativos, estando à frente de diversas outras profissões tidas como "nobres". De maneira geral, há uma tendência de redução dos empregos diretos na agropecuária e indústrias, setores estes que se caracterizaram como as melhores oportunidades no século que terminou. Fala-se que nos Estados Unidos, nos próximos dez anos, estes dois setores representarão não mais que dois por cento dos empregos daquela economia, ficando para o comércio e serviços o grande filão.

Empresas prestadoras de serviços e comerciais já estão predominando nos grandes centros (São Paulo, Nova Iorque, Londres etc.), abrindo constantemente oportunidades profissionais para, entre outros profissionais, contadores.

Por outro lado, as instalações de empresas de ponta, em muitas regiões prósperas como a grande São Paulo, vão substituindo as chamadas carcaças industriais que foram símbolos de pujança num passado bem recente. Estas empresas contratam os chamados "serviços ligados à produção", envolvendo engenharia, publicidade, informática, design, finanças, imprensa, contabilidade etc.

A queda dos empregos na indústria de transformação é notória em função de reestruturações, automações etc. Entretanto, o crescimento constante nos empregos em serviços ligados à produção (que buscam mão-de-obra qualificada e remuneram melhor) é inquestionável.

Na concepção de Echeverria (1999, p.88):

"Nesse segmento empresarial privado, vejo o espaço para o profissional da Contabilidade, pois, onde houver uma empresa, haverá um Contador. Seja na sua criação, ou no acompanhamento de seu desenvolvimento, a empresa obrigatoriamente contará com este profissional. Poderá atuar - ainda como auditor (checando a saúde das empresas) ou em atividades voltadas à Contabilidade Administrativa".

A própria história, como ressalta Lopes Sá
(1997, p.15), confirma: " a contabilidade nasceu com a civilização e jamais deixará de existir em decorrência dela".

\section{Situação atual da profissão contábil}

Estamos diante de uma nova etapa na área contábil, ou seja, a fase mecânica cedeu lugar à fase técnica que está cedendo lugar à fase da informação. Sendo assim, fica evidente a queda nos empregos, pelo fato de estarmos vivendo um momento de transição. Para Perez (1997,p.68), o objetivo da profissão contábil:

"Vai mais além de acumular cifras, para preparar um balanço para efeitos impositivos. Vai mais além de registrar automaticamente uma ou várias operações: um software adequado pode produzir melhor as rotinas".

Os profissionais contábeis são necessários a estes serviços ligados à produção (engenharia, informática, pesquisas, design...) e outros.

Um campo novo de trabalho, também com muita perspectiva para o profissional contábil, é o chamado "terceiro setor". São organizações privadas autônomas, normalmente sem a finalidade de distribuir lucro aos seus proprietários ou diretores, revertendo todo o lucro para a própria entidade, buscando o bem estar da sociedade. Algumas vezes são chamadas também de Organizações Não Governamentais, ou Associações Culturais, ou Fundações Privadas, ou entidades Sociais Organizadas etc.

Nos Estados Unidos, os recursos gerados por estas instituições estão na ordem de US $\$ 660$ bilhões por ano, representando um crescimento quatro vezes maior que as empresas que distribuem lucro aos acionistas. No Brasil, este setor, que está em estado embrionário, já representa dois por cento dos empregos. A maior multinacional brasileira hoje é considerada uma organização eclesiástica evangélica.

A preocupação em evitar fraudes nestas instituições e a exigência das organizações internacionais, como o Banco Mundial e o Banco Interamericano de Desenvolvimento, de parecer de auditorias reconhecidas para liberarem recursos para essas entidades, proporcionaram à 
Trevisan Auditores Independentes aumento de sua clientela em torno de $10 \%$.

A responsabilidade social destas organizações (principalmente na prestação de contas, que é o ponto fundamental para a sua sobrevivência), a criação e a estruturação das fundações, os projetos e orçamentos de longo prazo, a captação de recursos, o controle e aplicação destes recursos, a controladoria destas instituições... são alguns exemplos de atividades para o profissional contábil. Em reportagem produzida pelo jornal $\bigcirc$ Globo $^{1}$, com base na pesquisa da Ray \& Bernedtson, empresa especializada na busca de executivos, a contabilidade foi considerada uma das atividades profissionais mais promissoras nesta transição de séculos. No artigo Prontos para $o$ trabalho do futuro, são destacadas onze profissões que cada vez mais vêm se distinguindo no mercado globalizado, entre elas a contabilidade com um novo perfil (o novo contador deve dominar economia internacional e o processo de gestão de sua empresa, além de ter grande visão de negócio). Não visão de Andrade (2000, p.61):

"As informações geradas pela contabilidade devem propiciar aos seus usuários base segura às decisões, pela compreensão do estado em que se encontra a Entidade, seu desempenho, sua evolução, riscos e oportunidades que oferece".

Por repetidas vezes temos também falado que a contabilidade é a única profissão que oferece um leque amplo de alternativas profissionais, permitindo mais de duas dezenas de opções de especialização. No entanto, é tão simples, de acordo com Mussolini (1994, p.79):

"O contador deve se conscientizar de que a valorização se fundamenta, essencialmente, em dois pontos básicos: a) indiscutível capacidade técnica e b) irrepreensível comportamento ético".

Todavia, apèsar das inúmeras vantagens, não existem milagres no processo de obtenção de sucesso profissional nesta área ou em qualquer atividade. Há necessidade do desenvolvimento equilibrado das "duas pernas" que permitem a realização profissional: a competência e a ética.

\section{Competência e habilidades}

A evolução humana corresponde ao desenvolvimento de sua inteligência. Sendo assim, poderíamos explanar um pouco a respeito, antes de discutirmos sobre competências e habilidades.

Os seres humanos pré-históricos não conseguiam entender os fenômenos da natureza. Por este motivo, suas reações eram sempre de medo: tinham medo das tempestades e do desconhecido. Como não conseguiam compreender o que se passava diante deles, não lhes restava outra alternativa senão o medo e o espanto daquilo que presenciavam.

Num segundo momento, a inteligência humana evoluiu do medo para a tentativa de explicação dos fenômenos através do pensamento mágico, das crenças e das superstições. Era, sem dúvida, uma evolução, já que tentavam explicar o que viam. Assim, as tempestades podiam ser fruto de uma ira divina, a boa colheita da benevolência dos mitos, as desgraças ou as fortunas eram explicadas através da troca do humano com o mágico.

Como as explicações mágicas não bastavam para compreender os fenômenos, os seres humanos finalmente evoluíram para a busca de respostas através de caminhos que pudessem ser comprovados. Desta forma, nasceu a ciência metódica, que procura sempre uma aproximação com a lógica.

O ser humano é o único animal da natureza com capacidade de pensar. Esta característica permite que os seres humanos sejam capazes de refletir sobre o significado de suas próprias experiências. Assim, sendo, é capaz de novas descobertas e de transmiti-las a seus descendentes.

Hoje, espera-se que o contador esteja em constante evolução, além de possuir uma série de atributos indispensáveis nas diversas especializações da profissão contábil, não sendo mais possível sobreviver com aquela postura de escriturador, "guarda-livros", "despachante" e atividades burocráticas de maneira geral.

'Prontos para o trabalho do futuro. O Globo, Rio de Janeiro, 26 dez. 1999. Caderno Boa Chance 
Um profissional da área contábil é um agente de mudanças e, como tal, este profissional deve mostrar suas diversas habilidades. O contador é o "anjo-da-guarda" de uma empresa, tornandose seu profundo conhecedor, podendo desta forma atuar em sua continuidade e crescimento. Conforme Montaldo (1995, p.32), o contador:

"...deve desempenhar aqui um papel importannte nas negociações inter-regionais assessorando, pesquisando, trazendo informações e elementos que assegurem o fluxo de informação contínua, que leva a uma tomada de decisão racional; deve oferecer um serviço socialmente útil e, profissionalmente, eficiente, que não seja apenas fruto da experiência e da formação universitária recebida, mas também de seu compromisso de incrementar e renovar constantemente o caudal de seus conhecimentos em prol da unidade regional".

O contador deve se apresentar como um tradutor e não simplesmente como um apurador de dados. Não basta elaborar os relatórios contábeis/financeiros, mas fazer com que os gestores consigam entender o que esses relatórios estão informando. Sob este aspecto, um tradutor é aquele que consegue interpretar as informações e adequá-las à tomada de decisão com eficiência e rapidez. O profissional contábil, neste contexto, deve estar mais preocupado com a utilidade, transparência, clareza e objetividade das demonstrações contábeis para o usuário, do que com a beleza intrínseca dessas demonstrações.

Dentro de uma empresa, o contador é um "comunicador" em potencial, pois ele está em sintonia com todas as áreas como, por exemplo: produção, vendas, finanças etc. Nasi (1994, p.5) cita que:

"O contador deve estar no centro e na liderança deste processo, pois, do contrário, seu lugar vai ser ocupado por outro profissional. O contador deve saber comunicar-se com as outras áreas da empresa. Para tanto, não pode ficar com os conhecimentos restritos aos temas contábeis e fiscais. O contador deve ter formação cultural acima da média, inteirando-se do que acontece ao seu redor, na sua comunidade, no seu Estado, no seu país e no mundo. $\mathrm{O}$ contador deve ter um comportamento ético-profissional inquestionável. O contador deve participar de eventos destinados à sua permanente atualização profissional. O contador deve estar consciente de sua responsabilidade social e profissional".

Concordando com Nasi, acreditamos que seja importante o contador buscar e revelar as informações nas diversas atividades que compõem a empresa: nesta situação, o profissional contábil está se passando por um "repórter". A função de um repórter é buscar informações importantes, tratar estas informações sem distorcê-las e repassá-las fidedignamente, o mais breve possível. Neste aspecto, o profissional contábil desempenha papel semelhante.

Se o profissional contábil consegue deter informações vitais sobre a situação das empresas, pode desempenhar a função de Controller. Um exemplo recente desta habilidade foi percebido na Prefeitura do Rio de Janeiro. O Controlador Geral - cargo de confiança - não era cargo ocupado por funcionário do quadro técnico, e sim, por profissionais contadores.

A vantagem de deter informações imprescindíveis é a possibilidade de poder planejar, simular e criar diversas alternativas, as quais possibilitem à empresa atingir a sua meta, alcançando o sucesso.

Pensando bem, quem detém o controle de informações tem condições de avaliar, dentre diversas alternativas, a que poderá levar a empresa ao sucesso desejado. O objetivo, neste momento, é mostrar o profissional contábil atuando como um “avaliador”. Porém, este profissional estará atuando, também, como "consultor". Quando os dirigentes, governo, clientes, banco etc., desejam alguma informação, esta é obtida do profissional contábil.

Nas empresas, em algumas situações, há necessidade de se fazer alterações nos sistemas contábeis/financeiros, de forma a obter informações mais precisas ou mesmo corrigir alguns desvios, os quais são percebidos após a implantação do sistema. Nestes casos, quem atua juntamente com os analistas de maneira a auxiliar e agilizar as alterações é o contador. Porém, é muito comum, também, encontrarmos o contador no papel de analista, desenvolvendo sistemas 
no intuito de otimizar o processo de contabilização, bem como a obtenção mais rápida de dados e informações contábeis. Então, parecer ser possível a existência de um contador "designer".

Talvez, as habilidades citadas possam parecer um pouco de exagero, mas são fáceis de serem percebidas pelos que acompanham os diversos artigos e pronunciamentos em revistas, jornais, debates, palestras, congressos e seminários. Enfim, são muitos os que falam a respeito do crescimento da área contábil e as perspectivas da profissão.

Estes são alguns exemplos de habilidades destacadas para o exercício da profissão contábil. Seria impossível elencá-las todas.

Dentro da vocação e amplitude da visão de cada um, poder-se-ia falar de muitas outras habilidades. Ressaltamos, por último, uma habilidade que deve estar presente como suporte das citadas anteriormente, que é a de "pesquisador". Esta habilidade é essencial para o crescimento e aprimoramento do profissional contábil.

Em artigo de Otaviano Canuto publicado no jornal $\bigcirc$ Estado de São Paulo ${ }^{2}$ - Quanto custa uma reputação? - o autor critica a contabilidade tradicional que não reconhece gastos com $\mathrm{P} \& \mathrm{D}$ como Ativo (Investimentos), prejudicando, inclusive, o cálculo do PIB, não destacando os Ativos Intangíveis, provocando a supervalorização acionária. Assuntos como este têm que despertar na classe contábil um desejo profundo de pesquisa, da busca da verdade, de debates que só aqueles profissionais habilitados e competentes poderão fazê-lo.

\section{Desenvolvimento das habilidades}

São perfeitamente admissíveis e interessantes as habilidades elencadas anteriormente. O melhor é qué são estas habilidades que as empresas esperam encontrar nos profissionais que contratam; todavia, será possível encontrarmos, atualmente, um recém formado com pelo menos $30 \%$ das habilidades citadas? Se a resposta for talvez ou não, temos outra indagação: por que os recém formados não possuem tais habilidades?

A resposta para os questionamentos anteriores é óbvia, ou seja, está faltando comunicação entre as Instituições de Ensino e o mercado de trabalho. Não há como desenvolver as habilidades de comunicador ou intérprete, se os alunos, simplesmente, continuam estudando Português nas faculdades como "recordar é viver". Estamos necessitando com urgência de atualização nas grades curriculares, no intuito de atualizar a ementa e metodologia aplicadas em algumas disciplinas, e inserir novas disciplinas que permitam aos alunos se adequarem às novas tendências do mercado de trabalho.

No entanto, temos um outro aspecto a ser observado que é a interdisciplinaridade. Infelizmente, muitas vezes percebemos que os alunos são estimulados para o desenvolvimento de alguns itens fundamentais para o aprimoramento das habilidades citadas; o que ocorre, exatamente, é a falta de elos entre estes itens, ou seja, interdisciplinaridade.

Por exemplo, a disciplina Português, ou como algumas Instituições denominam "Português Instrumental", deveria ter como meta estimular e desenvolver no aluno a habilidade de expor as idéias de forma coerente em um texto.

Uma deficiência nessa área torna-se um problema real na hora de confeccionar um relatório ou expor a situação contábil da empresa em uma reunião. É importante também desenvolver habilidade na elaboração de análises descritivas. É muito comum, ao cursarem a disciplina Análise das Demonstrações Financeiras, os alunos desenvolverem os cálculos perfeitamente, entretanto, não conseguem expressar o que refletem aqueles valores através de análises descritivas.

Como abordado anteriormente, um profissional contábil deve ser um comunicador em potencial, e todos nós sabemos que, para desenvolver tal habilidade, há necessidade de inserir na grade disciplinas como marketing, cultura organizacional, com o objetivo de desenvolver nos discentes uma postura mais forte, para que sejam mais críticos, imponham suas opiniões,

¿Quanto custa uma reputação? O Estado de São Paulo, São Paulo, 22 de fev. 2000. Caderno de Economia. 
pois é notório o inverso, ou seja, ainda encontramos profissionais e estudantes com uma postura retraída, quieta, submissa. Todavia, no mercado não há mais espaço para profissionais com tal postura.

$\mathrm{Na}$ verdade, o que desejamos é mostrar que não basta conhecer o perfil do profissional desejado pelo mercado, mas sim buscar, através de pesquisas alternativas, que tais habilidades possam ser desenvolvidas durante a graduação, ou pelo menos parte delas.

\section{Postura ética}

A profissão contábil, assim como qualquer outra, é exercida na combinação da competência com a ética. Ou melhor, é o exercício da competência conduzida pela ética. A competência é fazer aquilo que é certo. A ética exige que seja feito de forma correta, consistente com a boa reputação da profissão.

Em nosso artigo "O contabilista, a Ética e a Bíblia”" destacamos que, de todas as profissões, o profissional contábil é o que mais está sujeito a partilhar de esquemas espúrios, já que sua atividade está intimamente ligada a dados, cifras, apuração de resultado, e, conseqüentemente, exibe dados que geram montantes referentes a impostos, taxas, dividendos, encargos, valor patrimonial da ação, lucro etc.

Há empresas que estão preocupadas em reduzir seus custos e desembolsos através de um planejamento tributário, de um orçamento operacional, de uma cuidadosa política de dividendos, de modernas técnicas de controles internos (no sentido de evitar desperdícios) e de outros instrumentos eficazes e sadios que proporcionam economia para as mesmas e benefícios para a nação.

Ninguém melhror que o profissional contábil, portador de conhecimentos na área fiscal, previdenciária, de custos, de auditoria, de orçamento e mesmo de outras áreas afins à contábil e de diversas habilidades, para coordenar e orientar este tipo de trabalho, bem como acompanhar este planejamento empresarial, comparando os dados reais registrados pela contabilidade com aquilo que foi planejado.

Entendemos que o profissional contábil deva ser o arquiteto principal da organização deste sistema que, em última análise, reduz o preço final do bem ou serviço que será consumido pela população, trazendo benefícios não só à empresa, como também a toda coletividade e a própria Balança Comercial, através de produtos mais competitivos no mercado externo.

Por outro lado, há empresas que, achando-se vítimas de uma carga tributária e previdenciária excessivamente onerosas, e até mesmo justificando-se em circunstância do elevado ônus financeiro imposto pelos bancos emprestadores de recursos e outros motivos, julgam-se no direito de reduzir os seus encargos e, conseqüentemente, seus desembolsos, através de omissão de dados contábeis, subtraindo fraudulentamente montantes devidos ao fisco ou a terceiros, procedimentos estes que levam à sonegação, fraudes, evasão fiscal etc.

Dessas empresas há ainda aquelas que, além de eximirem-se à legislação tributária, vão mais longe e, inescrupulosamente, oprimem seus empregados a situações constrangedoras como a omissão dos registros legais, descontos indevidos na folha de pagamento, omissão nos recolhimentos dos encargos sociais, remuneração indigna, demissões fúteis etc.

Tais lesões não param apenas nas áreas fiscais e trabalhistas, mas outros segmentos são atingidos por este tipo de empresário, trazendo enormes prejuízos às diversas camadas sociais. Sem dúvida, a impunidade de tais atos tem sido um estímulo sem limite para tais práticas em nosso país.

Todavia, nesta oportunidade, não queremos nos deter meramente no julgamento da conduta destes empresários. Queremos, sim, analisar o comportamento de profissionais vinculados a este tipo de empresa, de certa forma, embora muitas vezes involuntariamente, compartilhando deste esquema degenerado e nocivo para a maioria.

Quando os cursos de Contabilidade enfatizam somente a competência, esquecendo o lado ético, humano, religioso, formam um profissional

${ }^{3}$ Revista Brasileira de Contabilidade, n.58, 1986. 
"manco" (só a perna da competência se desenvolveu), proporcionando, quem sabe, um excelente profissional, mas um péssimo homem.

Poucas profissões se expõem tanto à corrupção quanto a contabilidade. Ao mesmo tempo que estamos tão ameaçados à sedução da corrupção, formamos os agentes que combatem ou contribuem decisivamente no processo de evitar a corrupção: auditores, investigadores de fraudes contábeis, peritos contábeis etc.

É provado que, em países onde a relação auditores externos/número de habitantes é maior, a corrupção é pequena (Holanda, Inglaterra, EUA,...). Por outro lado, em países como o Brasil, onde o número de auditores externos é irrelevante, a corrupção está livre para expansão sem limite.

De maneira geral, o profissional contábil gerencia todo o sistema de informação, os bancos de dados que propiciam tomada de decisões tanto dos usuários internos como os externos. Toda sociedade espera transparência dos Informes Contábeis, resultados não só de competência profissional, mas simultaneamente, de postura ética.

Novamente, voltamos ao mesmo discurso: como estamos formando os futuros profissionais? Não estariam as faculdades, através dos seus docentes, adestrando os discentes com aulas em que eles decoram os artigos constantes do Código de Ética do Conselho?

Voltamos ao mesmo ponto: é necessário um aprimoramento do conteúdo da disciplina ética, com o objetivo de evitarmos um profissional perneta.

Estudar o código de ética é fundamental, mas antes é primordial que o discente esteja consciente não apenas dos conceitos acerca da moral, crenças, costumes, sigilo, entre outras, como também tenha dentro de si internalizado estes conceitos. Só assim o discente estará apto a entender o cốdigo de ética e aplicá-lo sem decorar seus artigos. A ética fluirá naturalmente devido a conscientização desenvolvida na forma como a disciplina foi ministrada.

Todo este discurso se baseia na tentativa de nos alertar para as novas tendências do mercado, sem achar que basta criar uma disciplina chamada, por exemplo, Política de Negócios, e acreditarmos que estamos preparando o nosso discente dentro das exigências do mercado atual. Torna-se cada vez mais premente a pesquisa de novas metodologias de ensino e avaliação, com a finalidade de atender a demanda deste mercado de trabalho globalizado.

Devemos buscar o reconhecimento do profissional contábil pelo valor que ele adiciona à empresa.

\section{Conclusão}

Os dois lados da profissão contábil poderiam ser vistos:

a) Como lado bom, as oportunidades de mercado (com desemprego praticamente igual a zero, novos campos se abrindo e as diversas alternativas na condição de autônomo ou empresário) e retorno financeiro relevante em relação à média das profissões.

b) Como lado ruim é o quanto se está exposto às seduções espúrias do mercado. Nenhuma profissão está tão sujeita quanto esta à corrupção. De maneira geral, não se percebe uma preocupação das Instituições de Ensino e outros segmentos, de uma melhor preparação dos profissionais no que tange o lado ético, humano ou espiritual.

Em relação à competência, é notório, para todas as profissões, que não basta apenas ter um curso superior, dominar as disciplinas ministradas no curso de Contabilidade ou estar preso aos processos convencionais de ensino e aprendizagem. Há necessidade de se ir mais longe, de sair do tradicional e lembrar o antigo ensinamento: "quem pouco plantou, pouco colheu".

Em relação à ética, é fundamental o estudo constante do nosso excelente código de ética. É necessário ainda a busca de valores mais elevados, de princípios cristãos que norteiam a formação de homens e mulheres, munindo-os de dignidade, de transparência e de honestidade.

\section{REFERÊNCIAS BIBLIOGRÁFICAS}

ANDRADE, Ivan Dantas de. Fronteiras entre Circulante e Longo prazo. Revista Brasileira de Contabilidade, Brasília, DF, ano 24, n. 123, maio/jun, 1995. 
MONTALDO, Oscar. A realidade econômica internacional e a profissão contábil. Revista Brasileira de Contabilidade, Brasília, DF, ano 24, n. 92, mar/abr, 1995.

MUSSOLINI, Luiz Fernando. A função social da Contabilidade. Revista Brasileira de Contabilidade. Brasília, DF, ano 23, n. 89, nov/dez, 1994.

NASI, Antônio Carlos. A Contabilidade como instrumento de informação, decisão e controle da gestão. Revista Brasileira de Contabilidade, Brasília, DF, ano 23, n. 77, abr/jun, 1994.

PEREZ, Antônio Castilla. A profissão contábil e o futuro. Revista Brasileira de Contabilidade, Brasília, DF, ano 26, n. 103, $\mathrm{jan} / \mathrm{fev}, 1997$.

SÁ, Antônio Lopes de. História geral e das doutrinas da Contabilidade. São Paulo: Atlas, 1997. 